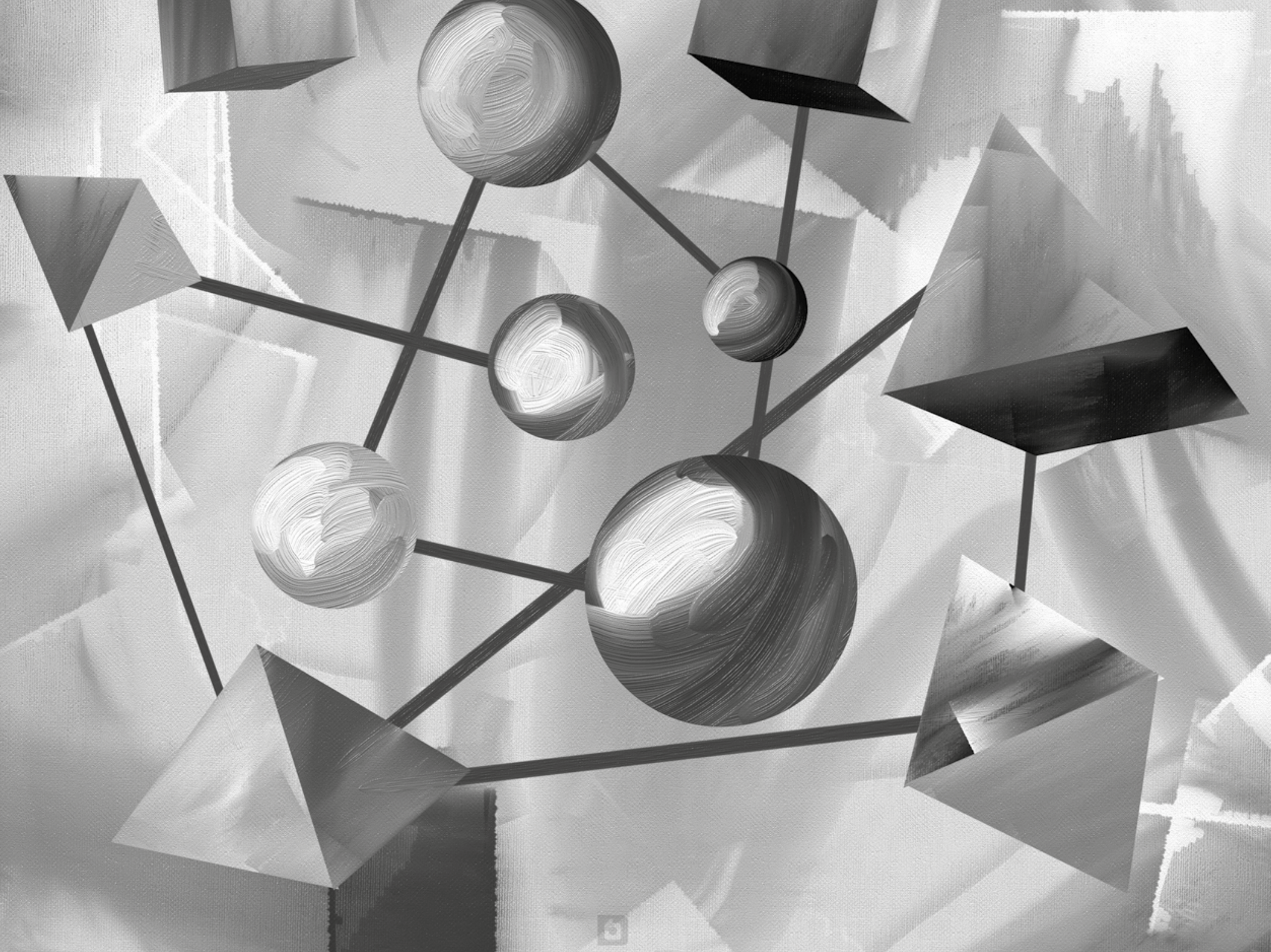

\title{
Territorios nómadas: nuevos lenguajes y subjetividades. Una experiencia sobre el lenguaje juvenil e infantil en la escuela
}

Nomadic Territories: new languages and subjectivities. An experience on youth and child language at school

Territórios Nómadas: novas linguagens e subjetividades. Uma experiência sobre a juventude ea linguagem da criança na escola 
Zulma Giovanna Delgado Ríos Luis Carlos Morales Carrillo² Nelson Custodio Rodríguez Rodríguez ${ }^{3}$
1 Maestría en Estética e Historia del Arte. Universidad Jorge Tadeo Lozano; Licenciada en psicología y pedagogía. Universidad Pedagógica Nacional; Maestra en Artes Plásticas y Visuales. Universidad Distrital Francisco José de Caldas; Investigadora Rednova (Idep, Investigaciones e innovaciones pedagógicas); Docente universitaria de la Licenciatura en Artes Visuales, Universidad Pedagógica Nacional; Docente de la Secretaría de Educación Distrital, Colegio Gabriel Betancourt Mejía, sede B.

Correo electrónico: delgadozulma12@gmail.com

2 Maestrante en Educación U.G.C.; Especialista en docencia universitaria U.C.C.; Licenciado en Ciencias Sociales U.G.C.; Investigador Rednova (Idep, Investigaciones e innovaciones pedagógicas); Docente de la Secretaría de Educación de Distrito. Colegio Gabriel Betancourt Mejía, sede B.

Correo electrónico: carlosmorca@yahoo.com

3 Maestrante en comunicación y educación. Universidad Distrital; Especialista en Pedagogía y docencia universitaria; Licenciado en Lingüística y literatura con énfasis en investigación literaria. UD. Investigador REDNOVA (IDEP, Investigaciones e innovaciones pedagógicas) 2013; Docente Secretaria de Educación. Colegio Gabriel Betancourt Mejía, sede B. Correo electrónico: elux777@yahoo.com

Fecha de recepción: 19 de junio de 2014 / fecha de aprobación: 21 de julio de 2014

\section{Resumen}

La escuela contemporánea es un reflejo de los constantes flujos de cambio en las dinámicas sociales, los cuales la han coaccionado en un lugar del desarraigo, de sujetos sin sentido de pertenencia e identidad hacia el lugar que habitan. Sin embargo, dicho contexto es el interés del proyecto Territorios nómadas como una reflexión permanente en el aula sobre aquel espacio significante. Integra los diferentes modos de expresión y el liderazgo de propuestas didácticas que fortalecen el reconocimiento de seres con decisión y participación política, autonomía, valores críticos y propositivos frente a las hacendosas situaciones que hoy enfrenta la sociedad colombiana.

Palabras clave: Pedagogía, territorio, identidad, subjetividad, crítico, comunicación.

\section{Summary}

The contemporary school is a reflection of the constant flow of change in social dynamics, which have been coerced into a place of rootlessness, of subjects with no sense of belonging and identity to the place they inhabit. However, this context is the interest Territories nomadic project as an ongoing reflection on classroom space that significant. It integrates the various modes of expression and leadership of educational proposals that strengthen the recognition decision beings and political participation, autonomy, critical and proactive against the industrious situations currently facing Colombian society values.

Keywords: Pedagogy, territory, identity, subjectivity, critical communication.

\section{Resumo}

A escola contemporânea é um reflexo do fluxo constante de mudança na dinâmica social, que foram coagidos a um lugar de desenraizamento, de indivíduos com nenhum sentimento de pertença e de identidade para o lugar que habitam. No entanto, neste contexto, é o projeto nômade Territórios de juros como uma reflexão permanente sobre o espaço da sala de aula que significativo. Ele integra os diferentes modos de expressão e liderança de propostas educacionais que fortaleçam os seres decisão de reconhecimento e participação política, autonomia, crítica e pró-ativa contra as situações industriosos enfrenta actualmente valores da sociedade colombiana.

Palavras chave: Pedagogia, território, identidade, subjetividade, comunicação crítica. 
as prácticas pedagógicas se relacionan en un contexto social _donde la reproducción y la producción cultural son hechos que pueden ser analizados. Por esa razón, se requiere la comprensión tanto de la meta-teoría como de los lenguajes que expresan dicha práctica. De tal forma, las orientaciones y relaciones creadas entre cultura y educación extienden las paradójicas situaciones de transmisión de un saber, de poder y soporte contextual, hacia la comunicación y la construcción del discurso propio de sus participantes.

Esencialmente, la acción pedagógica producida por el proyecto Territorios nómadas es enriquecida en el proceso de producción, discusión y apropiación de los sujetos por sus espacios de experiencia y sus subjetividades, momentos que interpelan los múltiples espacios en los que la complejidad de la enseñanza se hace presente. Por ello, se establece un escenario geográfico, sinérgico y analítico de las temporalidades e interacciones humanas que no se reducen a las fronteras del aula.
Con ello, no sólo se hace conciencia de la práctica pedagógica como mediadora del discurso del poder, sino como empoderamiento del discurso de trasmisión cultural. Entendiendo por cultural una conciencia lógica, más que ideológica, sobre el papel pedagógico de la escuela. Es decir, la escuela como un sistema que establece relaciones abiertas y pluridireccionales, que permite la reproducción cultural. Esta regla determina las exigencias del contexto y permite su expresión. Por ello, la pedagogía comparte un interés con la comunicación, pues lo único que está apartado de esta, es el silencio; las manifestaciones orales, corporales, escritas o diagramadas, infieren como un conjunto de circunstancias de discernimiento cultural sobre el contexto donde se sitúa el sujeto en relación con su familia, a las instituciones y el conocimiento.

Desde esa perspectiva la propuesta de Bernstein del siguiente diagrama sobre el contexto pedagógico, se apropia al interés del proyecto Territorios nómadas y sirve como categoría de análisis sobre las prácticas formativas.

\section{Práctica interactiva}

Poder - CLASIFICACIÓN

ENMARCAMIENTO

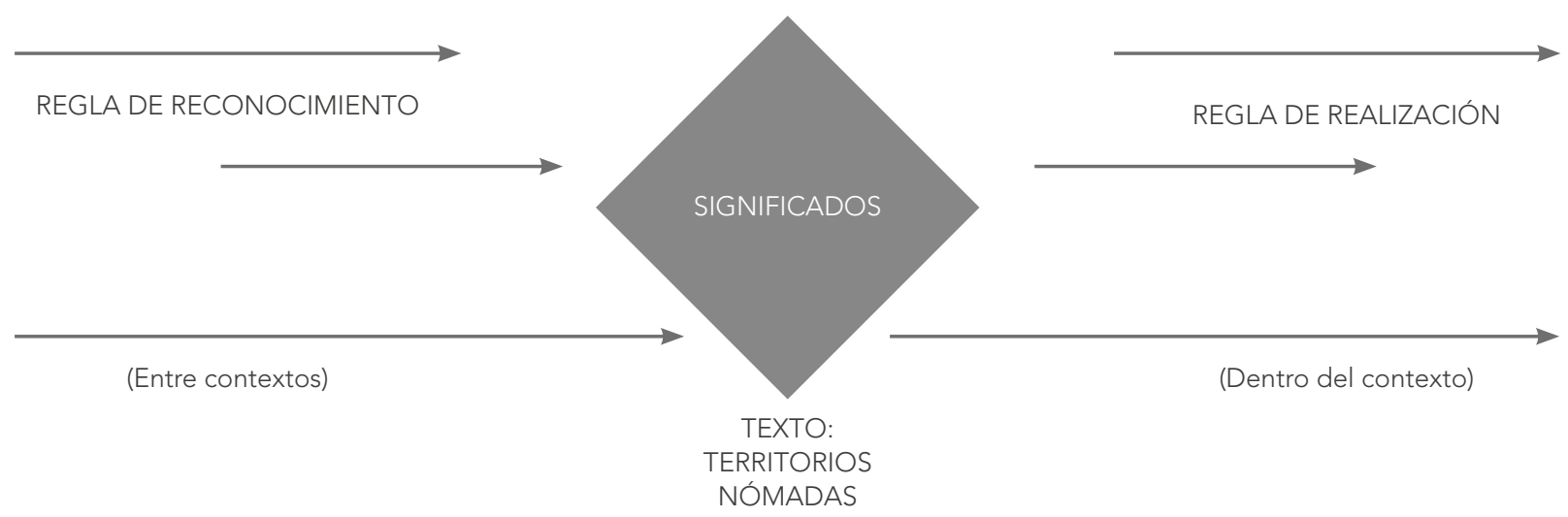

Gráfico 1. Tomado de B. Berstein (1998: 49), sobre el cual se inscribe intencionalmente la denominación del proyecto Territorios nómadas. 
En un nivel más concreto, el proyecto posee una estructura de reconocimiento que permite distinguir lo especial del contexto, teniendo en cuenta experiencias singulares desde lo cotidiano, lo personal, lo censurado y prohibido de las propias edades y contextos familiares, institucionales y comunitarios de los estudiantes. Así, los participantes logran identificar las relaciones de poder en las que están inmersos y su posición dentro de ellas, entablando una necesaria regla de realización personal, que apropie adecuadamente los significados simbólicos y selectivos de cada contexto. Por tanto, la comprensión de varios lenguajes y sentidos asignados al espacio por cada uno de los agentes que intervienen en este, permite el reconocimiento de distintos valores posicionales, y el lugar de las normas y de las relaciones abiertas o cerradas que se tejen en dichos escenarios; las cuales, se consideran pertinentes para la autorregulación de significados, legítimos y autónomos para la convivencia escolar. De modo que la apropiación y la identidad dejan de ser dispositivos conceptuales abstractos sobre los cuales no se tiene ninguna incidencia en la escuela para permitir un texto pedagógico esencialmente interactivo que exalta la sensibilidad, la experiencia estética y los lenguajes multimediales. De esta manera, el texto o producto de reflexión cultural es legítimamente apropiado y organizado por los estudiantes, que de manera consciente elaboran discursos sobre el lugar que les pertenece, habitan y comparten, a partir de herramientas artísticas o propias de la visualidad en medios digitales, redes sociales y otros formatos de comprensión y transmisión de las imágenes.

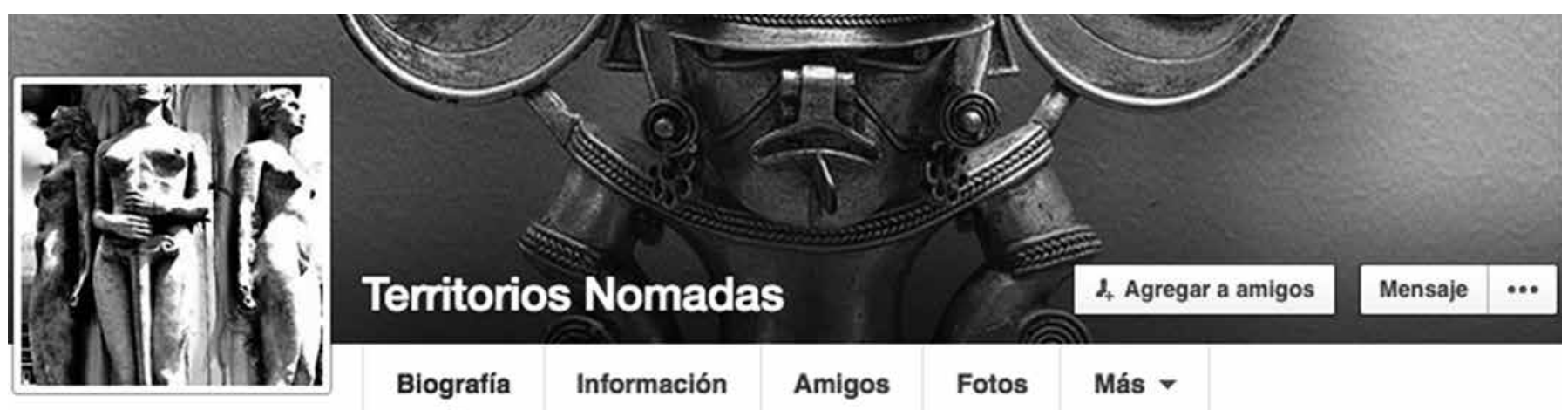

\section{¿CONOCES A TERRITORIOS?}

Para ver lo que ella comparte con sus amigos, enviale una solicitud de amistad.

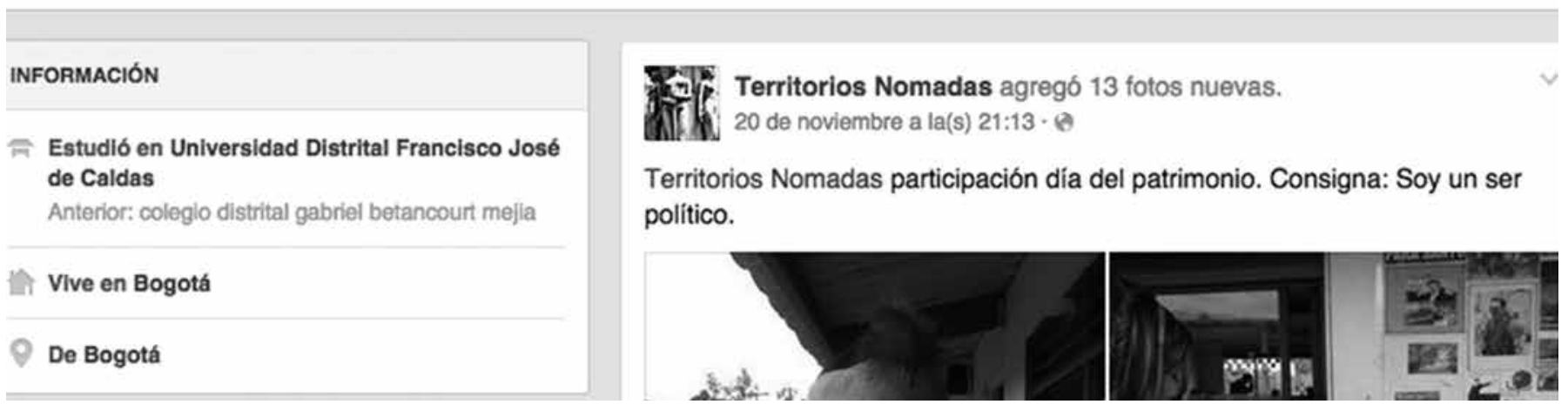

Imagen 1. Red social Territorios Nómadas, Facebook. 
Ahora bien, a nivel institucional, ¿qué significa una práctica pedagógica interactiva? significa que ha existido un cambio en los valores de clasificación y modelación del conocimiento, que cuestiona los criterios de distribución por edades y preocupaciones cognoscitivas aisladas, para integrar en un sólo discurso lo que piensan y expresan sobre un mismo problema, para este caso, el territorio. Gracias a lo anterior se cuestionan el conocimiento disciplinar y se acercan a la trasdisciplinariedad en los proyectos que logran dar cuenta del interés comunicativo y simbólico de las prácticas de enseñanza, con unas sencillas tareas, ejercicios en clase y encuentros de discusión sobre la gestualidad, la oralidad, la sonoridad que comparten o dispersan los significados precisos y unívocos del espacio geográfico, para preocuparse por el territorio habitado, personal, comunitario y estatal; es decir, sobre el lugar habitado y el espacio existencial, como múltiples maneras de nombrar el territorio.

Ha sido difícil cambiar el enfoque centrado en procesos y pensar la escuela como un escenario de investigación cualitativa que guie la reflexión sobre la práctica, más allá del aula de clase (ver tabla 1). Así como explicar el proceso pedagógico en el que se dinamiza la práctica docente por la actitud creativa y propositiva del estudiante. Por lo que la propuesta de Territorios nómadas es un texto abierto, producto de una práctica interactiva de saberes y procesos de identificación de la enseñanza que día a día nos va transformando.

A continuación, se resumen aquellos procesos que dan las categorías de análisis sobre el lugar, pasando por diferentes formas de expresión, que como hilos mágicos tejen la cartografía de nuestro hacer en la escuela.

\begin{tabular}{|c|c|c|c|c|}
\hline CATEGORÍA & $\begin{array}{l}\text { COMPONENTE } \\
\text { COMUNICATIVOS }\end{array}$ & DESCRIPCIÓN & TIPOS DE GESTIÓN & EJECUCIÓN \\
\hline Geografía & Lectura & Narrativas convergentes & $\begin{array}{l}\text { Estudiante } \\
\text { Familia } \\
\text { Docente }\end{array}$ & $\begin{array}{l}\text { Exploración fotográfica. } \\
\text { Creación de filminuto. } \\
\text { Plan lector de carácter } \\
\text { filosófico, crítico e histórico } \\
\text { sobre los lugares de } \\
\text { procedencia, del estar antes y } \\
\text { el ser ahora. }\end{array}$ \\
\hline Territorio & Escritura & $\begin{array}{l}\text { Nuevas formas de } \\
\text { expresión }\end{array}$ & $\begin{array}{l}\text { Estudiante Docente } \\
\text { Comunidad }\end{array}$ & $\begin{array}{l}\text { Vitrales, expresiones } \\
\text { en camisetas, murales, } \\
\text { exposiciones itinerantes por } \\
\text { la localidad, portafolio de } \\
\text { noticias y reflexiones. }\end{array}$ \\
\hline Cuerpo & $\begin{array}{l}\text { Oralidad } \\
\text { Expresar con el cuerpo y } \\
\text { con la tecnología }\end{array}$ & $\begin{array}{l}\text { Expresión y creación. } \\
\text { Juegos y destrezas } \\
\text { mentales y manuales. } \\
\text { Taller de construcción } \\
\text { de juegos con los } \\
\text { estudiantes. Texturas } \\
\text { y materiales. Rondas y } \\
\text { danzas. Performance, } \\
\text { vestuario }\end{array}$ & $\begin{array}{l}\text { Docente } \\
\text { Interinstucional }\end{array}$ & $\begin{array}{l}\text { Ponencia calidad de } \\
\text { educación. } \\
\text { Exposición arte sonoro. } \\
\text { Concierto culturas urbanas. } \\
\text { Performance y puestas en } \\
\text { escena. } \\
\text { El juego y las tradiciones } \\
\text { culturales. } \\
\text { Uso de la redes sociales } \\
\text { y blog de publicación de } \\
\text { experiencias. }\end{array}$ \\
\hline Memoria & Escuchar & Audición de experiencias & $\begin{array}{l}\text { Estudiante } \\
\text { Docente }\end{array}$ & $\begin{array}{l}\text { Capacitación y } \\
\text { reconocimiento de } \\
\text { experiencias sonoras. }\end{array}$ \\
\hline Identidad & Dibujar & Concurso de ilustración & Estudiante & $\begin{array}{l}\text { Culturas urbanas, logos y } \\
\text { diseños. }\end{array}$ \\
\hline
\end{tabular}

Tabla 1. Realizada por Zulma Delgado y Luis Carlos Morales, mayo de 2013. 
Con ello, la propuesta señala el camino hacia la pedagogía crítica, que desde la escuela de Frankfort ha buscado la emancipación cultural e intelectual del hombre de todos aquellos esquemas que perjudican el crecimiento social. Así que lo que se busca es la transformación de las prácticas docentes tradicionales y centralizadas, para disponer de espacios y acciones comunes multidisciplinarmente. Escenarios que involucran relaciones entre la historia, la política, el poder y el contexto; donde se promueve el compromiso del estudiante con la comunidad y con las acciones proyectadas como grupos de solidaridad para la autoafirmación y la transformación social, lo que significa la inserción del pensamiento crítico en la formación de sujetos políticos.

La cuestión metodológica está en saber apropiar y dirigir el saber natural del estudiante en su contexto para potenciar una lectura crítica y liberadora de la pulsión juvenil. Situaciones denominadas como conflictivas dentro de los parámetros del reglamento escolar, señaladas como actitudes de irreverencia, desacato y falta de participación e integración del estudiante con su colectivo. Actitudes que reflejan la distancia que existe entre el currículo estandarizado y los sujetos que interactúan, a través de prácticas de trasmisión de saberes desarticulados del contexto y los intereses del grupo de edades.

Por ello, la relectura de nuestros procesos docentes, el planteamiento de análisis sobre ciertas prácticas exitosas en la institución, reconocen el saber formativo y la capacidad transformadora de la pedagogía que potencia sujetos hacia la definición de su autonomía e identidad. Consideraciones que guardan estrecha relación con la comunicación, comprometidos con la articulación en la esfera pública, el contexto nacional y local, así como la comprensión de las libertades individuales y la justicia social, como saberes que discuten Paulo Freire y Peter McLaren dentro de la pedagogía autónoma y crítica respectivamente.

\section{Construcción de una experiencia}

La indagación investigativa ha propuesto el análisis trasversal desde diferentes prácticas educativas, así las áreas de español, sociales y artes integran caminos de construcción teórica y procesos de análisis sobre la convergencia del territorio en contingencias mediáticas -como el internet, las redes sociales, las imágenes audiovisuales, etc.-. Hecho

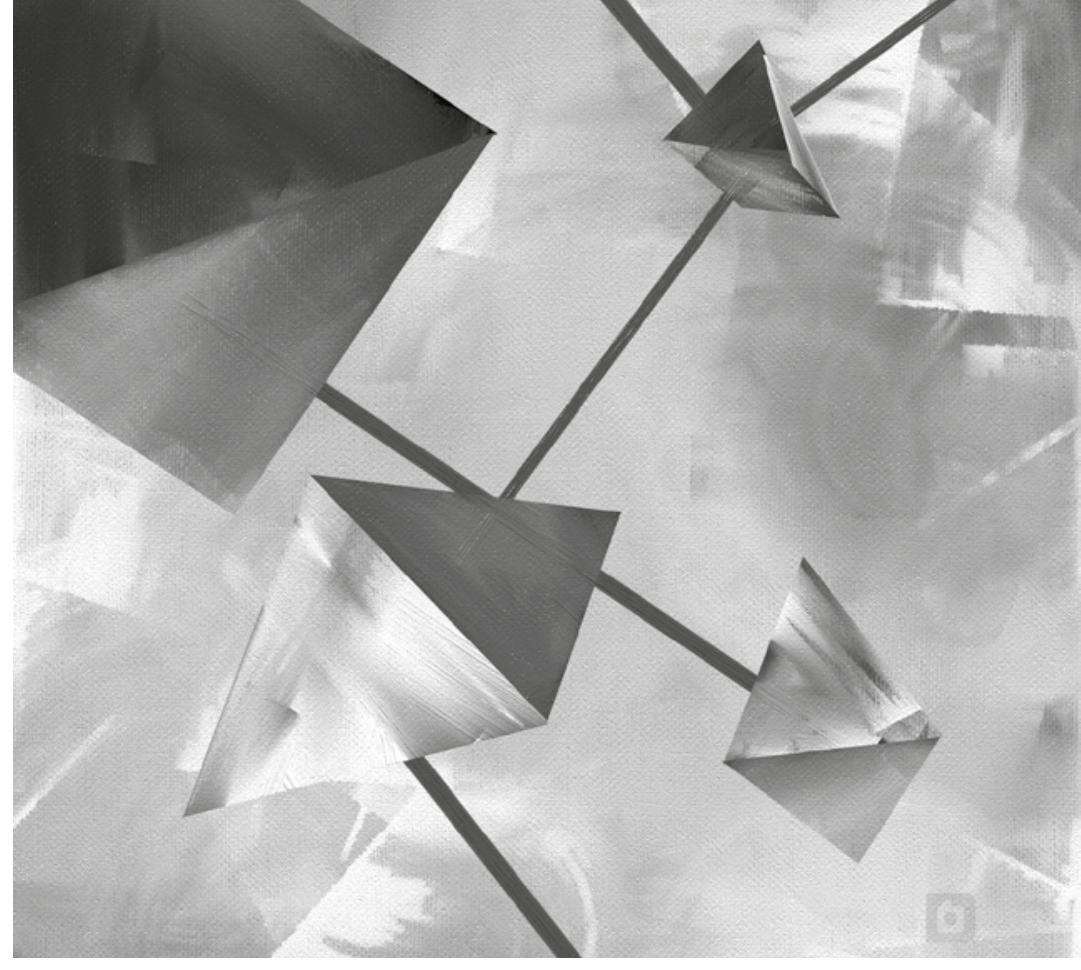

gracias al cual se ha retomando la importancia en la interconexión de experiencias como posibilidades de acción y la participación de los estudiantes en la cultura (Jenkins, 2008), vinculándolos a esferas comunitarias y a la gestión de grupos de discusión, mediante prácticas de aula que favorecen el pensamiento crítico y las reflexiones de identidad.

\section{El contexto de la práctica educativa}

En este escenario se plantea una pregunta por la convergencia, por las contingencias mediáticas, por las narrativas de la práctica educativa y la experiencia del estudiante, como ejes de pensamiento sobre la labor docente. El problema fundamental está en la identificación del territorio como un espacio nómada, de relaciones pasajeras, inestables y sin asentamiento en la identidad. Rasgos poblacionales de una comunidad en crecimiento, de una niñez y un Estado joven que deben lograr ciertas intermediaciones en su contexto contemporáneo, reconociendo como dice Scolari (2008), una explosión de los medios digitales, ciertas prácticas de producción y consumo en relación con hipertextos y nuevas narrativas que permiten el conocimiento y las relaciones humanas.

El contexto situado en la mediación y las narrativas trasmediáticas propone un territorio en tensión con la normatividad en la escuela tradicional. El choque entre la transmisión del saber enciclopédico y la reflexión propositiva que hace el estudiante, desde actividades centradas en la visualidad, permite definir los intereses de este proyecto, como reflexiones juveniles sobre el arte, la expresión y la convivencia escolar. 


\section{La intervención pedagógica}

Entonces la noción de territorio es comprendida como horizonte de sentido entre las relaciones del individuo con su entorno, y como un campo de discusión político-pedagógico para la reflexión educativa, provocada por la experiencia docente sobre un lugar específico. Así, dicho concepto parece tener múltiples referencias. Primero se identifica como un lugar que ocupan las cosas; segundo, como pertenencia a un contexto físico o como campo de interacción de diversos actores, y por supuesto, como un ente que se transforma en la experiencia. Por ello, no se pretende afianzar una definición, al contrario, el territorio parece pertenecer a la dinámica del ser en su tiempo.

Por esta razón es parte del lugar donde los estudiantes descubren sus propias narrativas, utilizando como lenguaje integrador la experiencia de diversas prácticas comunicativas -experiencia desde las artes visuales, musicales, corporales, narrativas: oralidad y escritura-. De hecho los docentes participantes han buscado por diferentes medios la comprensión y uso de diferentes estrategias de experiencia multi-textual que permitan interpretar y anunciar la complejidad de dichos espacios juveniles. En la práctica, se propone que el estudiante sea quien cree los contenidos, los analice y participe de sus construcciones, por medio de los murales, las fotografías, los filminutos, los conciertos; pues la compresión de antiguos y nuevos modos de comunicación los hacen partícipes de herramientas del lenguaje emergentes, como por ejemplo las redes sociales, las instalaciones objetuales, las acciones performáticas y otras intervenciones en su comunidad educativa.

De tal forma se integran los medios, los lenguajes, formatos y estilos a una reflexión sobre la posproducción de los bienes culturales (Borriaud, 2001). De hecho, la cultura es el escenario de construcción y apropiación de la vida contemporánea, no sólo en el contexto de la tradición e identidad de un pueblo con su lugar de origen, que corresponde a la lectura localizada del territorio, sino como construcciones mediáticas que reprograman el repertorio de imágenes y modelos simbólicos ya instituidos, y establecen nuevas geografías y dinámicas topográficas sobre el lugar. Entonces, el proyecto reconoce diferentes formas de mapear un territorio de sentido (Cerda, 2009).

La actividad pedagógica, vista desde este lindero conceptual, difumina las fronteras del conocimiento centrado en el mode- lo cognitivo, para ser un procedimiento activo de elementos interconectados, como un relato que continuaría y reinterpretaría las narrativas tradicionales en la enseñanza, por una metodología más acorde con la dinámica contemporánea. Lo cual hace referencia al término Estética relacional (Bourriaud, 2001) en el que se describe una sensibilidad colectiva frente a formas de participación en el conocimiento, que no se refiere exclusivamente al uso mediático de las TIC'S, sino a la profundización de experiencias donde el sujeto genera discusiones, y es parte propositiva y autónoma frente al saber cultural y social que le es heredado. Efectivamente, aparece el lenguaje en red ${ }^{4}$ para articular las producciones culturales e instaurar una forma crítica de sociabilidad, donde el docente es un facilitador de dichas narrativas trasmediáticas, repensando y reconsiderando el espacio mismo de su práctica y los modos de comunicación entre pares académicos.

La actividad pedagógica es así formadora de un pensamiento crítico y una actitud activa en el proceso de desarrollo, donde se reutilizan redes de signos y significaciones, propios de los estudiantes y de la dinámica pedagógica, para pensar sobre aquellas formas, ya producidas, de apropiación historicista, de lenguajes tradicionales y modelos de una sociedad costumbrista. Es decir, se alinea en la era de la posproducción, en tanto reutiliza las formas culturales de enseñanza, de trasmisión de contenidos y de saberes especializados, para disponer del lenguaje propio de las narrativas contemporáneas. Se supera la ideología de lo nuevo en el pensamiento moderno, por la recodificación y apropiación de lenguajes juveniles. El proyecto Territorios nómadas utiliza una figura similar al saber, donde el sujeto atenúa las fronteras entre recepción y práctica, produciendo así diferentes encuentros y desencuentros con el conocimiento.

\section{Análisis de los componentes}

En este punto volvemos al valor de la convergencia (Jenkins, 2008) que se refiere al uso de diferentes plataformas mediáticas que se disponen como eje de reflexiones pedagógicas, que favorecen la circulación de las mismas experiencias y la definición de un cambio cultural a partir de la acción y motivación de los participantes, lo que los lleva a buscar información, y a crear relaciones y contenidos críticos frente a la significación del territorio.

4 Para ampliar la información visitar los siguientes links : http://territoriosnomadas20.wix.com/territoriosnomadas http://www.youtube.com/watch?v=ipgsRAYaE5s 
A partir de este proyecto educativo, el lenguaje se reconoce como un sistema productor de símbolos, donde el locutor establece sus propios diálogos y se le da la palabra al estudiante, a sus relaciones y a sus interconexiones con el saber propio de la historia y del arte, entre otros medios expresivos. Por ello, es necesario hacer el análisis de dichas prácticas desde cierto as- pecto formal -estética y metodológica de la práctica educativa-, las representaciones - de una identidad cultural y unas políticas sociales-, el fortalecimiento de un pensamiento político -identidad y prácticas democráticas que favorecen la convivencia en la escuela- y por último, las prácticas educativas como medio -desde lo corporal, lo territorial y lo simbólico-.

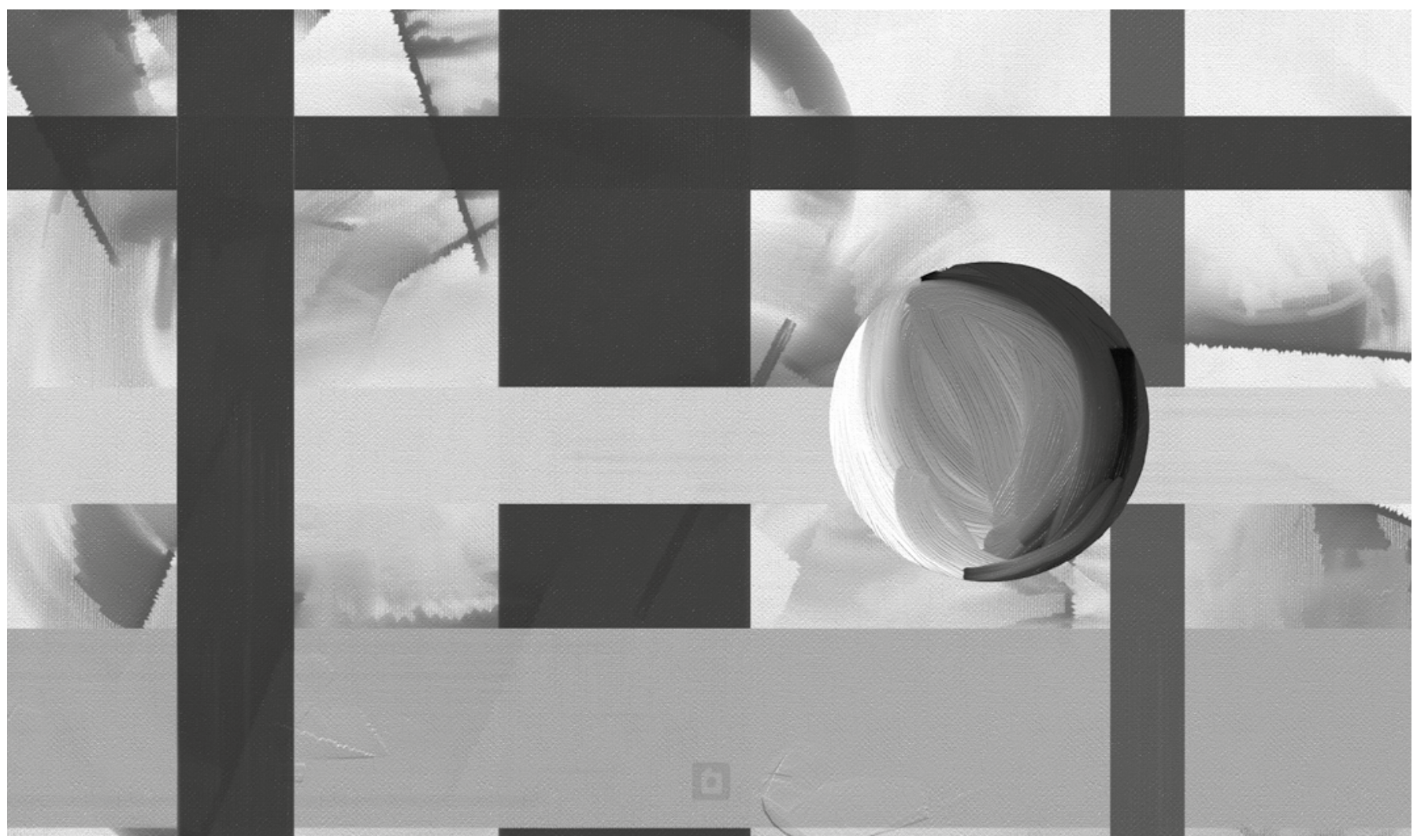

Así, uno de los caminos retratados por los estudiantes busca identificar esta alusión al lugar heterogéneo, más allá de declarar las debilidades nacionalistas, entreteje un espacio vacío, ilustra de cierta manera, "la situación fragmentaria de la topografía cultural del hombre contemporáneo" (Shayegan, 2008: 110). La fibra del tiempo en dos figuras yuxtapuestas exige una mirada atenta a los desplazamientos, los fraccionamientos y las insinuaciones políticas de unas coordenadas de lugar, época y sucesión; es decir, de los valores de posición que toman los estudiantes y sus propuestas creativas, críticas y analíticas sobre el territorio. La cuestión aquí es producida por el uso de un patrón mundial de asociaciones, que se asemejan al concepto de hibridación de Nestor García Canclini en el que las diferencias culturales y el diálogo intercultural, subvierten las entidades hegemónicas, dando paso a las clasificaciones imaginadas, la trasgresión de sentido, la desestabilización del signo y su resemantización.

Del mismo modo, el lugar personal destinado por los estudiantes supone un espacio libre de toda ideología de dominación y subversión, que va en contravía con los principios de orden pedagógico en la escuela, que en otros tiempos permitían percibir perspectivas, paradigmas narrativos, formalismos históricos o visuales -currículo y pedagogía-, y ahora, configura 
un territorio desalojado del sentido de identidad. De tal forma, el territorio se convierte en una zona de conflicto, tanto a nivel personal como nacional.

Desde el proyecto se entiende la posibilidad de creación y realización de prácticas pedagógicas que recurren a cierta circulación extendida, alejada del propio cuerpo y registro social del momento histórico, para acercarse al lenguaje simbólico como una modalidad esquizofrénica. Es decir, aquel signo que va creando imágenes fortuitas, sin lograr mantener una identidad antes de pasar a otra. Signos volubles, mutantes, en perpetuo camino de ser tomados y abandonados, lo que le da una proyección reflexiva a la escuela y a las propuestas docentes, más allá de una medida académica.

Este primer análisis hace referencia a la descripción del cuerpo ausente, la transformación del territorio - ese gran hiperespacio posmoderno que define Jamenson- como la capacidad de auto-organizar perceptivamente todas y cada una de las características para cartografiar cognitivamente cada uno de sus lugares, se propone ahora, un cuerpo desorientado, descentrado, multilateral y global, donde, "como sujetos individuales, nos hallamos presos” (Jamenson, 1995: 104).

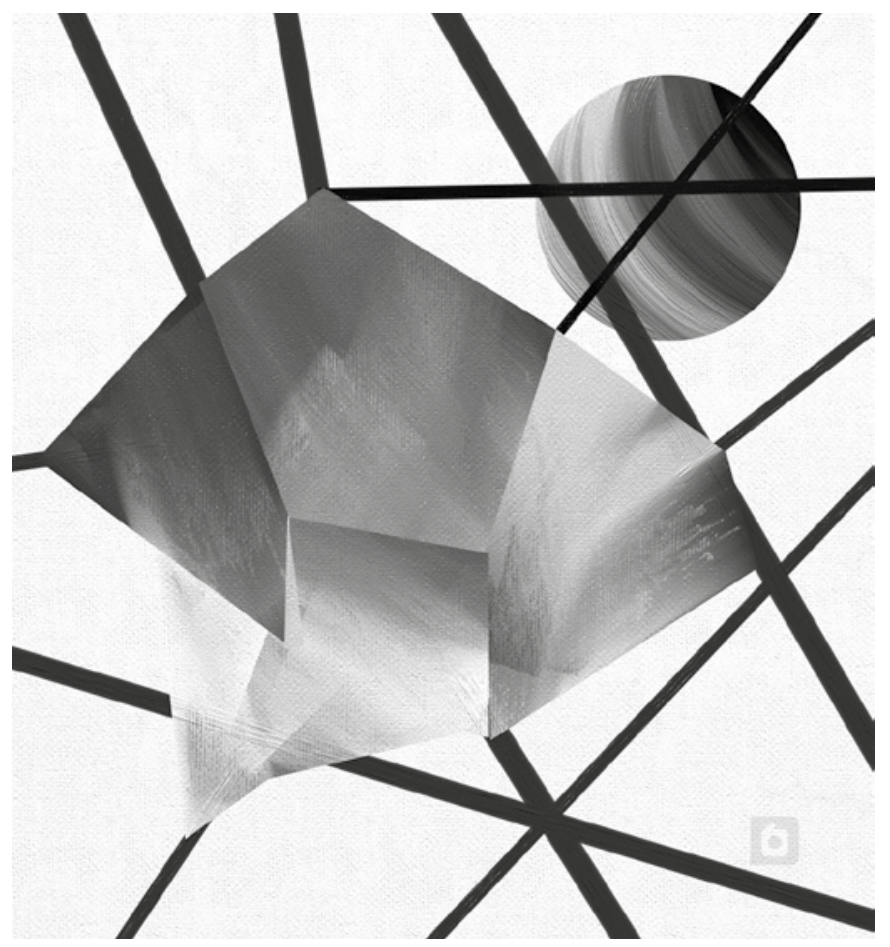

Entonces, el proyecto Territorios nómadas se propone como lugar de interacción para las prácticas pedagógicas, que no son totalitarias, ni excluyentes, sino analíticas y propositivas. Lo que se está trazando aquí es una reflexión sobre la cartografía educativa hegemónica, social o cultural, donde los espacios heterogéneos constituyen el mismo plano histórico y cognitivo, que pueden retomarse como estructuras políticas que trazan ciertas particulares sobre un territorio específico, pero apuntan a estructuras globalizantes.

Por tanto, las geografías planteadas por los estudiantes y docentes se constituyen, no como espacios de encuentro e identidad, sino como espacios para el disenso y los discursos subalternos que encarnan las instituciones al examinar el sentido ético de los acostumbrados actos de violencia y trasgresión sobre el territorio nacional. Se propone una primera categoría de análisis como Territorio de conflicto, de memorias políticas y sociales, quizá más cercano a una estética geopolítica (Jamenson, 1995) como postura de pensamiento visual sobre una identidad gastada en conflictos, donde lo desterritorializado pasa a ser reflejo del estado decadente y precisamente, anti-identitario.

Ante este panorama, el estudiante es tomado en cuenta desde su corporalidad, como agente que sufre la desterritorialización y debe encarar la realidad nacional con herramientas de poder, como sus propias narraciones y anécdotas reflexivas, que evidencien una verdadera corporeidad frente a aquel "espacio sin distancia" (Zuñiga, 2008: 14), esto exige tanto a la pedagogía como a todas sus disciplinas académicas. Por ello las expresiones corporales y revestimientos creados para expresar sus propias ideas sobre el territorio abarcan una experiencia corporal contundente, por ejemplo los trabajos sobre el vestuario y los performance que anudan esta temática a su propia corporalidad. Aquí se devela un segundo planteamiento sobre el territorio en tensión, que abarca la definición y aceptación de su propia imagen como los señalamientos puntuales a la estructura de poder dentro de la escuela; reconociendo al otro como un individuo de derechos y de subjetividades diferenciales. Entonces, el territorio no trata de meras circunstancias de la naturaleza, sino del cuerpo en relación con el lugar y las imágenes mediáticas, sin ninguna distancia temporal, lo que crea un territorio de tensión.

Sin embargo, la intervención del proyecto que acá se menciona no da cuenta exclusivamente del problema geográfico o intersubjetivo. Por ello, se plantea una tercera profundidad argumentativa que hace referencia al territorio, expansiones y narrativas, como 
formas en las que se construye el tejido social e incrementa su valor en la práctica educativa desde la misma expresión de los participantes, lo anterior, para responder a la pregunta ¿Cómo contribuir a la conformación de un estado de pensamiento político?, ¿cómo se potencia el sentido de pertenecía hacia la localidad y la institución educativa desde sus experiencias y expresiones personales?

Así, a lo largo de estos años en la implementación y montaje del proyecto Territorios nómadas, se han dispuesto diversos caminos de discusión y construcción sobre el sentido del contexto en la educación. La escuela se plantea "nuevos" retos, que han de ser abordados por los maestros y la comunidad educativa como una experiencia sinérgica, consciente y propositiva sobre el territorio. De acuerdo con esto, el proyecto ha liderado procesos narrativos y creativos sobre los espacios comunes tanto a niños como a jóvenes, se pueden enumerar rápidamente aquellos más cercanos a su realidad: el cuarto, sus objetos personales, la escuela, la ciudad y el planeta.

Dichos encuentros han permitido a los jóvenes discusiones principalmente frente a la normatividad que les rige en estos momentos; es así, como en varios relatos los estudiantes escriben: "me prohíben usar ropa distinta al uniforme", "me dicen que no me pinte las uñas de colores", "que debo traer el pelo recogido", "que no abrace a nadie", "debo ser feliz con lo que hay". Entre otras ideas que giran en torno a la privacidad de su propio lugar, donde son ellos quienes dirigen, ordenan, dan lugar y nombre a las cosas.
Por ello, la visión de territorio que han generado los jóvenes de la institución Gabriel Betancourt Mejía sede B, en estos años de procesos académicos e intelectuales ha sido diversa, pues el reconocimiento de su propia geografía ha cruzado las fronteras de una identidad, ha generado diferentes tensiones a partir del difícil hábito de pensarnos a nosotros mismos y del proceso de reconocimiento de las diferencias que esto conlleva; esto se debe en parte a la multiplicidad de orígenes, seguido de la carencia en el sentido de pertenencia, que en algunos ha logrado borrar sus orígenes, sus raíces y el sentido de habitar esta tierra.

Por consiguiente, la definición de la idea de territorio ha pasado por los tres estadios enumerados: territorio en conflicto, que hace parte de una memoria social y política en el país; luego, territorio en tensión, donde las subjetividades y reconocimientos corporales crean una dinámica más participativa del estudiante en relación con su entorno; para finamente abarcar un territorio de expresiones y narraciones donde se analizan las relaciones entre lo que el sistema educativo, político y económico del país ofrece frente a las aspiraciones del estudiantado.

En esas instancias, la escuela se propone como un escenario de pensamiento, que busca superar la manera restrictiva e impositiva del saber académico, por un interesado marco para la construcción del sujeto político, creador de expresiones e ideas de cambio. Un sujeto que revela el sentido social de los nuevos medios tecnológicos, donde el espacio para la convivencia debe ser apropiado y utilizado con pertinencia por los mismos agentes de la educación. 


\section{Referencias}

Bernstein, B. (1998). Pedagogía, control simbólico e identidad. Madrid: Ediciones Morata, S.L.

Carlon, M. \& Scolari, C. (2009). El fin de los medios masivos. El comienzo de un debate. Buenos Aires: Crujía.

Casey, Edward S. (2005). Earth-Mapping. Artists Reshaping Landscape. Minneapolis, London: University of Minesota Press.

Cubides Cipagauta, H. (2007). Foucault y el sujeto político: ética del cuidado de sí. Bogotá: Siglo del Hombre Editores.

Heidegger, M. (1994). Construir, morar, pensar. Traducción de Eustaquio Barjau. Conferencias y articulos. Barcelona: Serbal.

Jenkins, H. (2008). La cultura de la convergencia de los medios de comunicación. Barcelona: Paidós.

Jamenson, F. (1995). La estética geopolitica. Cine y espacio en el sistema mundial. Buenos Aires Ediciones Paidós Ibérica S.A. .

Jamenson, F. (1985). Posmodernismo y sociedad de consumo. En Foster, H. La posmodernidad. Primera Edición. Barcelona: Editorial Kairos, S.A.

García Canclini, N. (2008). Diferentes, desiguales y desconectados. Mapas de la interculturalidad. Barcelona: Gedisa Editorial.
Scolari, C. (2008). Hipermediaciones. Elementos para una teoría de la comunicación digital interactiva. Barcelona: Gedisa.

Zúñiga, R. (2008). La demarcación de los cuerpos. Tres textos sobre arte y biopolitica. Santiago de Chile: Ediciones Metales pesados.

\section{Artículos de internet:}

Bourriaud, N. (2001). Posproducción: la cultura como escenario: modos en que el arte reprograma el mundo contemporáneo. http:/ /www.catedragarciacano. com.ar/wp-content/uploads/2009/11/nicolas-bourriaud-completo1.pdf. Fecha de recuperación: mayo 13 de 2013.

Cerda, D. (Septiembre de 2012). La web 2.0 y las nuevas geografías. Artículo en recurso informático: http://noticias.uarcis.cl/index.php/ opinion/sociedad/944-web-20-y-la-nueva-geografia.

Quijano, A. (2003). Colonialidad del poder, eurocentrismo y América Latina. Lander, E. (comp.) La colonialidad del saber: eurocentrismo y ciencias sociales. Perspectivas latinoamericanas. Buenos Aires: Consejo Latinoamericano de Ciencias Sociales (Clacso). Disponible en la World Wide Web: http://bibliotecavirtual.clacso.org.ar/ar/libros/lander/ quijano.rtf. Fecga de recuperación: julio de 2000.

Scolari, C. (2008). Convergencia, educación y narrativas transmedia en la nueva ecología de los medios. Recurso informático http://www.relpe.org/ wp-content/uploads/2010/11/RELPE_convergencia_scolari-.pdf. Fecha de recuperación: 23 de septiembre de 2013. 


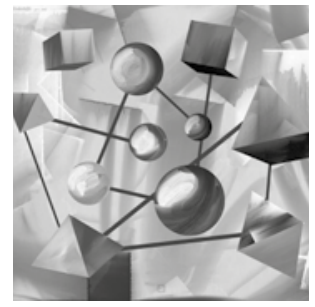




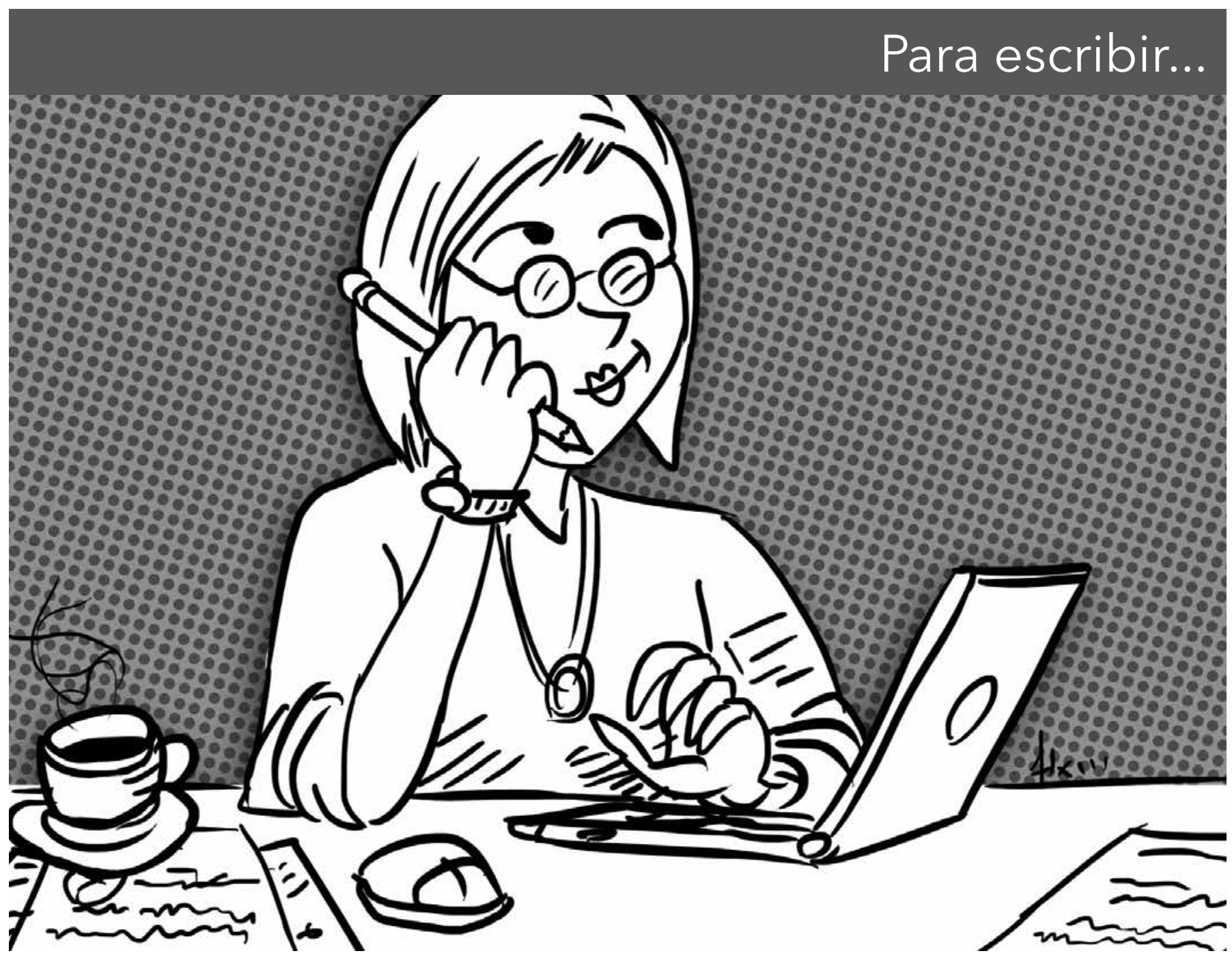

Revista Educación y Ciudad Instrucciones para los autores y autoras de artículos 